Flame Radiation Committee on experimental furnaces at Ijmuiden in Holland and at Stockholm. Two types of trial are carried out. In 'performance trials' the effect of input variables on the distribution of emissivity is investigated by radiation pyrometry, while in 'combustion mechanism trials' probe methods are used to determine distributions of the more fundamental variables, such as suction pyrometer temperature, fraction of combustion, Pitot velocity and soot content. Such experiments provide much valuable information on furnace heat transfer, and general correlations are already emerging of the dependence of flame characteristics, such as flame length, temperatures and emissivities in various parts of the flame, on input variables such as nozzle design, atomizing agent, preheat temperatures and type and quantity of fuel.

Subsequent discussion reflected the diversity of the topics raised by the original contributions which may perhaps have seemed a little bewildering to the uninitiated. Such diversity, however, enables the newcomer to the field to form a balanced impression of current trends in combustion research and often gives rise to valuable cross-fertilization of ideas among workers in the various branches of the subject. In fulfilling these aims, the meeting was thoroughly successful.

F. J. WIINBERG

\section{ANIMAL MIGRATION}

CECTION D (Zoology) of the British Association $\checkmark$ held a symposium on "Migration" in Bristol on September 2, with Mr. Peter Scott, vice-president of the Section, in the chair. A paper on "Recent Data on Movements of Desert Locust Swarms", by Dr. R. C. Rainey, Z. Waloff and H. Sayer, was read by Dr. Rainey. Recently some reasonably accurate estimates of the numbers of individuals in a locust swarm have been made by taking out samples obtained by spraying portions of the swarms with insecticides. A density of 70 locusts per square yard has been found, so that a swarm 8 square miles in area would contain some three thousand tons of locusts. These eat their own weight of food every day, and it is thus easy to understand how the recent invasion of Morocco has caused damage estimated at $£ 4 \frac{1}{2}$ million.

Studies of orientation within the swarms have been made by taking photographs vertically upwards, coupled with pilot balloon observations of local wind conditions. It is found that individual locusts are orientated at random within the swarm. But this does not mean that the individual's flight is wholly independent of its neighbours'. The swarms show marked cohesion in turbulent air, and there is a strong 'edge effect' which causes locusts leaving the swarm to turn back into it. The movement of the swarm as a whole tends to be downwind, a conclusion agreeing with previous work in which the recorded tracks of locust swarms were correlated with weather charts. This downwind movement of the swarms will in the course of time inevitably lead them to the 'zones of convergence' where winds from different directions meet. The air in such zones must necessarily rise, leading to condensation, rain and moist ground conditions. The very lack of positive orientation of the swarm will thus ensure its arrival in an area which is suitable ecologically. The socalled 'intertropical fronts' are examples of such zones. Occasionally thero may be a carrying-over beyond the zone in the downwind drift, as occurred last October when desert locusts appeared at several points in Britain. A film of locust swarms seen from the ground and the air was then shown.

In the discussion, Dr. Rainey said that it seems that the locusts maintain contact with one another within the swarm by visual means. Their auditory sensitivity is insufficient for this purpose. The fact that a swarm was once picked up by a ship's radar four hours after sunset cannot be cited as evidence for non-visual orientation, because the swarm was so large that there would not have been sufficient time for it to have become dispersed. While there is a possibility that the locusts appearing in England were brought by a ship, this is unlikely because of the simultaneous appearances at scattered points and the precise correlation with weather conditions. Large numbers of dead locusts were found at sea up to the latitude of Lisbon on the same day. It is impossible for locusts to keep flying actively for the thirty hours or so needed to reach England, but they can remain airborne for such periods by gliding at intervals, a habit Mr. Scott had noticed in Morocco. In 1865 substantial numbers of locusts came aboard a ship 1,200 miles off West Africa.

Mr. T. A. Stuart next spoke on "The Local Migrations of Brown Trout". He said that sea trout make local movements-the resulting concentrations being exploited by fishermen-as well as their true migrations to and from the sea. The benefit of this behaviour to the species is that far more fish can grow to maturity on the plentiful food of the sea than could if they remained in the home brook. The brown trout was originally thought to be nonmigratory ; but it has now been shown, by catching and marking samples of the fish, that there is a definite movement downstream to the lochs, where the fish matures. The adult fish migrates back up the streams at about the same time, though the two movements do not necessarily coincide. Occasionally precocious young males will stay and fertilize incoming females before starting on their own migration, but young females always require the extra year in the loch to lay in sufficient reserves for egg production.

The trout has a strong homing tendency, and, of many hundreds marked, none has afterwards been recovered in a stream other than that in which it was originally captured, except when the latter has been blocked. From 1952 the fry has been marked in this way, so that it is definitely known that the individual was born in a particular stream. Again strong homing tendencies have been demonstrated. Experiments have been made in which ripe fish moving up a stream are removed and released in streams on the opposite side of a large reservoir into which the streams emptied, a distance of more than a mile. No fish was recaptured in the stream to which it had been transferred; but about half those released were recovered and all save two were back in the original stream from which they had been removed. The successful homers did not only have to detect the mouth of the home stream once they were in the reservoir, but also actively to leave the foreign stream, swimming downstream against the mass of incoming fish for whom that particular stream was home. Mr. Stuart could not offer any explanation for the way in which the fish could re-orientate themselves in this manner. He thought it unlikely to be based on the detection of chemical 
factors, a view he maintained in the subsequent discussion when the work of Hasler was mentioned. This latter worker has claimed that fish can 'smell' the difference between streams from the difference in their organic contents.

Dr. G. V. T. Matthews then presented a review of recent work concerning "The Sun's Role in Bird Orientation". There is now plenty of evidence that birds can home from areas of which they have no previous experience. In some cases this may be due to a simple random wandering, but often the birds show initial homeward orientation followed by such swift returns that they must have flown pretty well straight home. Two types of navigation may be distinguished, the first being a limited navigation in which birds orientate themselves and fly in one direction only, fixed either by their instinctive behaviour or by a learning process. This suffices so long as the starting and finishing points always bear the same relation to one another; but the birds will be led astray if displaced in a novel direction. Secondly, there is a form of complete navigation in which the birds can orientate themselves and fly towards home no matter in which direction they were released. Many remarkable results have been obtained, culminating in the Manx shearwater that flew three thousand miles home across the Atlantic in twelve days.

The simple 'compass' navigation has been studied under laboratory conditions by making a bird indicate a certain direction. Bower birds, building their constructions with a rigidly northward orientation, provide a natural experiment, but the most important work has been done with caged migrants whose restless movements showed a strong directional component. Birds can also be trained to take up a direction by food conditioning. The prime orientating factor is undoubtedly the sun, since when it is lacking or 'displaced' by mirrors, the birds' orientation becomes random or is displaced accordingly; also, an artificial source of light is treated as if it were the true sun. The sun compass is fully developed in night migrants, and it is probable that they pick up a direction around sunset.

The complete navigation has been studied by observing the orientation behaviour of birds in the field under different conditions. Again the sun is an essential factor, only random orientation occurring in its absence. There are indications that some type of 'grid' navigation is concerned which, depending on the comparison of stimuli, becomes ineffective close to home. The main controversy is on whether the sun is still only concerned as a compass, or whether the bird can interpret the sun's position in the sky sufficiently to provide the 'grid'. This would require observation of the sun's movement along its arc, extrapolation of that movement, accurate angular measurements and an accurate internal chronometer. These are difficult to credit, but are theoretically within the capacity of the birds' sensory equipment. Some experiments aimed at confusing such a navigating mechanism have produced results supporting the hypothesis, which is the most promising one at the moment, though it cannot be finally accepted as yet. A film of the homing experiments with Manx shearwaters was then shown.

An extended discussion followed in which the required sensitivity of the bird eye, the stability of the head in flight and the accuracy of the internal chronometer received attention. Dr. Matthews said that claims of orientation within ten seconds of release could probably be referred to directional tendencies and not to position-fixing. Dr. J. Verwey, from Holland, a distinguished foreign guest at the meeting, contributed much to the discussion; he directed attention to recent work by Sauer which apparently shows that caged migrants can pick up a direction from the (unclouded) night sky, and gave an account of the orientation of sand-hoppers.

\section{G. V. T. MaTTHews}

\section{INFORMATION THEORY}

\section{THIRD LONDON SYMPOSIUM}

$T$ HE mathematical theory of information has undergone considerable broadening and clarification during the past few years, and it is being studied, and applied to the design of experiments, by people in very varied fields-in particular, communication engineering, taxonomy, linguistics and neurophysiology. Two symposia have previously been held in London, in 1950 (Nature, 167, 20; 1951 ) and in 1952 (Nature, 170, 1051; 1952); and, as a further experiment, another inter-disciplinary and international meeting was held at the Royal Institution during September 12-16 last. This meeting was attended by two hundred and fifty representatives from fifteen different countries, including a large body from the United States and representatives of the Academy of Sciences of the U.S.S.R. The meeting was organized by Dr. Colin Cherry, of the Electrical Engineering Department, Imperial College of Science and Technology, London.

The symposium was opened by Prof. Bálth van der Pol, of Geneva. From the start, the discussions were numerous and lively, showing that, in spite of their variety of background, the participants enjoyed a considerable degree of mutual understanding through their common study of information theory. The subject is, of course, mathematical and forms a part of scientific method; it does not relate solely to telecommunications (whence it arose) but concerns all phenomena which are 'communicative' in nature, for which representations or scientific models are made, and to which true measures can be applied, precisely and numerically. The early promise offered, that information theory would provide a valuable unifying force between various specializations, is cortainly being fulfilled.

The first day of the meeting was devoted to a review of the fundamental concepts and the various measures which may be applied to 'information rates'. Prof. J. L. van Soest, of the Netherlands, discussed the essentially discrete, or quantal, nature of communicable information and some of its consequences for the theory. A paper by Mr. G. Spencer Brown on the difficulties underlying definition of 'randomness' raised discussion to the level of debate -as might be expected of that thorny subject. But the concepts of 'randomness' of a stochastic source and of the degree of 'disorder' of finite sequence are of great importance to the whole theory ; information theory may yet resolve some of the difficulties.

On the same day, Dr. D. Gabor, and also Dr. W. Meyer-Eppler (Germany), extended the application of the theory to physics; in particular, to optics. Finally, the relevance of 'information' in the theory of games was considered by Dr. R. Farquharson (Great Britain). 